\title{
On the Psychology of the Advantaged: How People React to Being Overpaid
}

\author{
Susanne L. Peters · Kees van den Bos • \\ Johan C. Karremans
}

Published online: 28 June 2008

(C) The Author(s) 2008

\begin{abstract}
Based on the idea that overpaid people are in conflict between hedonic principles (i.e., what makes them pleased) and what they believe to be right, two studies tested the hypothesis that it should be relatively difficult for people to make satisfaction judgments regarding outcomes in which they are being advantaged. In line with this hypothesis, Study 1 demonstrated that response latencies of satisfaction judgments were longer when participants were being overpaid, compared to when they were underpaid or equally paid. Study 2 extended these findings by demonstrating that people required more time to make satisfaction judgments when they were overpaid in the context of a close relationship (i.e., in which the conflict between hedonic and concerns for the other's need should be stronger) than when overpaid in the context of a non-close relationship. Theoretical implications regarding the social-cognitive processes underlying reactions to overpayment are discussed.
\end{abstract}

Keywords Equity $\cdot$ Justice $\cdot$ Overpayment $\cdot$ Conflict $\cdot$ Response latencies

The institutions of society favor certain starting places over others. These are especially deep inequalities. Not only are they pervasive, but they affect men's initial chances in life; yet they cannot possibly be justified by an appeal to the

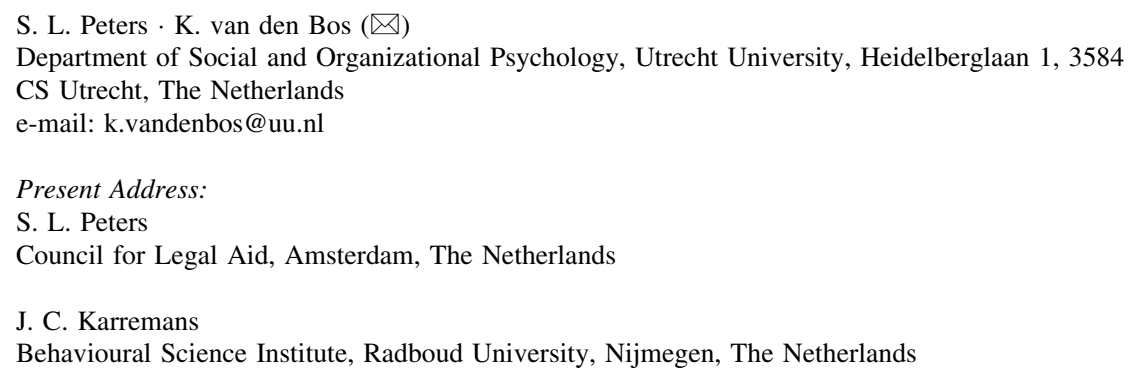


notions of merit or desert. It is these inequalities, presumably inevitable in the basic structure of any society, to which the principles of social justice must in the first instance apply.

Rawls (1971/1999, p. 7)

As Rawls (1971/1999) rightfully noted, societies favor certain people over others. In this article we try to understand the psychology of the advantaged. More specifically, we will explore how people react to being overpaid relative to another person who has contributed a comparable amount of input. To this end, we will base our line of reasoning on equity theory (e.g., Adams, 1965), as this is probably the most developed framework for understanding how people react to being overpaid.

Equity theory concerns what people think is equitable and fair and how people react to fair and unfair outcomes (Adams, 1965; Walster, Berscheid, \& Walster, 1973; Walster, Walster, \& Berscheid, 1978). The basic justice principle underlying equity theory is a balance between the contributions and rewards of two persons. Equity theory states that inequity exists whenever a person perceives that the ratio of his or her own inputs and outcomes do not match the ratio of another person's inputs and outcomes (e.g., Adams, 1965; Walster et al., 1973; Walster et al., 1978). Inequity results for people not only when they are relatively underbenefitted, but also when they are relatively overbenefitted. Thus, both disadvantageous inequity (underpayment) and advantageous inequity (overpayment) are inequitable payments. We would like to argue, following Jacques (1961) and Tyler, Boeckmann, Smith, and Huo (1997), that being overpaid is probably the most intriguing outcome distribution studied in equity research, because being overpaid creates a mixedmotive situation; an issue to which we will return below. Building on and extending Adams and others' work (Adams, 1965; Walster et al., 1973; Walster et al., 1978), in this article we will focus on overpayment distributions and, when appropriate, we will pay attention to other outcome distributions (i.e., underpayment and equal payment) as well.

Equity theory has shown convincingly that insights into how people react to being overpaid play an important role in various kinds of situations and therefore should be a key issue for social psychologists (see, e.g., Adams, 1965; Berkowitz \& Walster, 1976; Montada, Schmitt, \& Dalbert, 1986; Walster et al., 1973). For example, in organizational settings it is easy to find examples of the importance of understanding how people deal with being overpaid (e.g., Adams, 1965; Adams \& Freedman, 1976; Greenberg, 1982). Furthermore, research on intimate relationships has revealed that being better off than your partner can play an important role in how people react to issues in their intimate relationships (e.g., Mikula 2003; Van Yperen \& Buunk, 1990).

Because of the important role that overpayment plays in society as well as in people's lives, a lot of social psychological studies have been conducted to try to understand how people react to being overpaid. For example, in the 1960s, Jacques (1961) and Adams (1965) started the inquiry into this fascinating topic, and since then many researchers have further studied this frequently occurring instance of injustice. Researchers have shown that overpaid people try to restore equity (Adams, 1965; Walster et al., 1973, 1978), tend to feel only moderately 
satisfied with their outcome (Adams, 1965; Buunk \& Van Yperen, 1991; Van Yperen \& Buunk, 1990; Walster et al., 1973; Walster et al., 1978), and try to justify their advantage, for example, by adjusting the types of comparisons that they make (Austin, 1977; Mikula, 2003).

In this article, we would like to extend these insights. More specifically, we will argue that overpaid people are in conflict between what makes them pleased (i.e., hedonic concerns) and what they believe to be right (i.e., equity concerns; needs of the other person), and hence reactions to overpayment involve cognitively more complex judgment processes than reactions to underpayment and equal payment. We will also explain why this is an important, and previously unknown, contribution.

\section{Reactions to Being Overpaid}

On the basis of equity theory (e.g., Adams, 1965; Austin, McGinn, \& Susmilch, 1980; Austin \& Walster, 1974; Buunk \& Van Yperen, 1989; Van den Bos, Lind, Vermunt, \& Wilke, 1997), it can be argued that, when forming judgments of outcome satisfaction, individuals who are faced with inequity will feel distress and will be less satisfied than individuals who are faced with equity. As noted by Adams (1965): "There can be little doubt that inequity results in dissatisfaction"(p. 283). Equity theory therefore predicts and finds that people are only moderately satisfied with being overpaid (e.g., Adams, 1965; Buunk \& Van Yperen, 1991; Van Yperen \& Buunk, 1990; Walster et al., 1973; Walster et al., 1978).

We argue here that, in addition, people who are confronted with overpayment have to deal with conflicting social motives when forming judgments of outcome satisfaction. As Jacques put it, when describing human reactions to overpayment: "There are two powerful and opposing sets of forces inside each of us which determine our behavior" (p. 143). We propose, following Messick \& Sentis (1983), that when people are confronted with overpayment there is a conflict between hedonic principles and equity concerns, or in other terms, a conflict between what they want and what they believe to be right. From this proposition follows that when people are overpaid, there is one source of negative affect and one source of positive affect: The negative source is the fairness-based feeling of being unjustly advantaged (e.g. Montada, 2002; Montada et al., 1986), whereas the positive source is the egoism-based pleasure of receiving a relatively good outcome (cf. Van den Bos, Lind, Vermunt, \& Wilke, 1997; Van den Bos, Wilke, Lind, \& Vermunt, 1998). Thus, when people are being overpaid they are assumed to be in conflict between what makes them pleased and what they believe to be right. This mixed-motive quality of reactions to overpayment has also been recognized by more contemporary social psychologists (see, e.g., Loewenstein, Thompson, \& Bazerman, 1989; Messick \& Sentis, 1983; Peters, Van den Bos, \& Bobocel, 2004; Van den Bos et al., 1997, 1998; Van den Bos, Wilke, Lind, \& Vermunt, 2006). 


\section{The Current Research}

According to our knowledge, to date there have not yet been empirical tests using appropriate process measures that indeed show that overpaid people are in conflict when reacting to being overpaid. Here, we would like to provide data that support this suggestion. In order to do so, we base two studies on the rationale that if people are indeed influenced by conflicting sources, it should be relatively difficult for them to sort out how to respond toward the conflicting forces that are exerted on their reactions (e.g., Fiske \& Taylor, 1991; Kunda 1999). When people are influenced by conflicting sources, they are pulled in different directions and we argue that it should take some time to choose between these sources. Specifically, we propose that it will take people more time to make satisfaction judgments to being overpaid, compared to outcome distributions in which the above mentioned conflict is not experienced (i.e., underpayment and equal payment). This suggestion is tested directly in Study 1.

In Study 2, we continue this line of reasoning and make it more difficult for people to respond to being overpaid. That is, in Study 2, participants are being overpaid either in the context of a close relationship or are being overpaid in the context of a non-close relationship. In a close relationship, the conflict between egoistic hedonic concerns and concerns for the other person's needs should be relatively stronger than in a non-close relationship (Clark \& Mills, 1979), and hence satisfaction judgments to overpayment should be especially difficult.

\section{Study 1}

In Study 1, participants responded to a manipulation of outcome distributions. The study was constructed following earlier research by Van den Bos et al. (1998, Experiment 1). The outcome that participants received was held constant across conditions, and we varied whether the outcome was equal to the outcome of a comparable other person (equal payment), better than the outcome of the other person (overpayment), or worse than the outcome of the other person (underpayment). Main dependent variable was the time that participants needed to make outcome satisfaction judgments. Our hypothesis was that people would need more time to respond to being overpaid compared to being equally paid or underpaid.

Method

\section{Participants and Design}

Seventy-four female students at Utrecht University participated in the study and were paid for their participation. Participants were randomly assigned to one of the three outcome conditions (overpayment versus underpayment versus equal payment). 


\section{Experimental Procedure}

Participants took part in the study after participating in another study that explained the tasks they were expected to complete. The studies lasted a total of $30 \mathrm{~min}$, and participants were paid 4 Euros for their participation. On arrival at the laboratory, participants were led to separate cubicles, each of which contained a computer with a monitor and a keyboard. The computers were used to present the stimulus information and to measure the dependent variables.

In the first study we explained to participants that they were expected to read a scenario and to answer some questions regarding the scenario. It was then explained to them that it was important to respond to these questions as quickly and accurately as possible; therefore, they were expected to keep their index fingers right above the two answer-buttons. It was explained to them that they should press the 'yes/agree'button (the z-button was labeled as such) when they agreed with the statement presented to them, and that they should press the 'no/disagree'-button (the ?-button was labeled as such) when the disagreed with the statement presented to them. After this, they could practice the manner in which they were expected to respond in answer to some insignificant questions.

In the actual study it was explained to participants that they were again expected to read a scenario and to answer some questions regarding the scenario. And it was again explained to them that it was important to respond to these questions as quick and accurate as possible. It was explained to them that they should press the 'yes/ agree'-button when they were satisfied with the statement presented to them, and that they should press the 'no/disagree'-button when they were dissatisfied with the statement presented to them. Again, participants could practice with the manner in which they were expected to respond.

After this, participants read the scenario and answered the questions that constituted the dependent variables. First, participants were asked to imagine the following situation:

In the dorm where a friend of yours lives a room is vacant, for which you are going to apply. You know your friend pays 200 Euros for a comparable room.

This was followed by the outcome manipulation. Participants read the following sentences (manipulated information in italics):

You are informed that the rent that you will have to pay is 150/200/250 Euros.

After this, participants were asked how satisfied they were with the rent they had to pay $(1=$ dissatisfied, $2=$ satisfied $)$. The time that participants needed to answer this question served as the main dependent variable. When participants had answered this question, they were thoroughly debriefed and paid for their participation. The response time was measured from the moment participants could read the amount of money they had to pay until the moment they pressed one of the two buttons. 
Results

\section{Satisfaction Judgments}

Participants' satisfaction judgments showed a significant effect of outcome, $\chi^{2}(2)=48.55, p<.01$. As expected, these results showed that satisfaction judgments about being underpaid and overpaid differed significantly from each other, $\chi^{2}(1)=20.22, p<.01$; that satisfaction with equal payment and underpayment differed significantly from each other, $\chi^{2}(1)=45.91, p<.01$; and that satisfaction with overpayment and equal payment differed significantly from each other, $\chi^{2}(1)=6.41, p<.03$. When equally paid, more participants were satisfied with their outcome $(100 \%)$ than when overpaid $(70 \%)$, and when overpaid, more participants were satisfied with their outcome than when underpaid $(0 \%)$. This shows that we have successfully replicated the usual findings on satisfaction ratings in equity studies (Adams, 1965; Buunk \& Van Yperen, 1991; Van Yperen \& Buunk, 1990; Walster et al., 1973; Walster et al., 1978).

\section{Response Latencies}

Our main dependent variable was the time participants needed to indicate their outcome satisfaction judgments. To minimize the impact of long response latencies we followed procedures by Fazio (1990) and excluded one participant from our analyses who deviated more than three standard deviations from the mean. We then conducted an analysis of variance (ANOVA) which showed a significant main effect of the outcome manipulation, $F(2,70)=4.22, p<.02$. To interpret this effect we conducted a contrast analysis (Kirk, 1982) in order to find out if the response latencies in the overpayment condition indeed differed from those in the other two conditions. This analysis showed that in the overpayment condition, participants took significantly longer to give their satisfaction judgments than participants in the other two outcome conditions, $F(1,71)=7.22, p<.01$. Overpaid participants took significantly longer $(M=1.6, S D=0.9)$ to give their satisfaction judgments, compared to participants who were underpaid $(M=1.3, S D=0.6)$ and equally paid $(M=1.1, S D=0.40)$. Underpaid and equally paid participants did not differ significantly in the time needed to make satisfaction judgments, $F(1,71)=1.83$, $p=.18$ (note that this latter contrast was orthogonal to the contrast of overpayment versus equal payment and underpayment we used in the first contrast analysis).

\section{Discussion}

The results of this study provide support for our hypothesis. People need more time to make satisfaction judgments about being overpaid, compared to being underpaid or equally paid. These findings thus support our suggestion that when people are being overpaid, they indeed are more in conflict about how to respond, whereas they are less in conflict when they are underpaid or equally paid. 
In Study 2 we wanted to extend and complement these findings. By making the conflict about how to respond more difficult, people should take more time to respond when being overpaid. One way to strengthen the conflict people experience would be to have them overpaid relative to a person with whom they have a close relationship. Clark and Mills (1979) described close relationships as relationships in which the partners are each motivated to act for the needs of the other, regardless of the expected reciprocal outcome for the self. Based on this research and other research concerning closeness (e.g., Aron, Aron, Tudor, \& Nelson, 1991), we reasoned that when people are overpaid in reference to a friend (as compared to being overpaid in reference to an unknown other), they may be more motivated to consider the outcomes of the other person in the situation, and therefore be less interested in solely their own outcomes. Therefore, we argue, it should be more difficult for people to decide how to respond to being overpaid relative to a friend than relative to an unknown other. Based on this assumption, we expected people to need more time to respond to being overpaid in reference to a friend than when they are overpaid in reference to an unknown other.

\section{Study 2}

Study 2 was constructed following the experimental paradigm developed by Van den Bos et al. (1997, Experiment 2) in which participants completed tasks together with another participant and learned that their own task performance was comparable to the other participant's task performance. In the current study, we focus on the outcome distribution of greatest interest for this article: The outcome that participants received for their performance was better than the outcome received by the other participant. We varied whether the other participant was a friend of the participant or an unknown other whom they had not met before. Participants who brought a friend were said to be linked to their friend, and participants who did not were said to be linked to an unknown other. Our main dependent variable was the time that participants needed to make outcome satisfaction judgments. These judgments were measured on 7-point scales in order to replicate the findings of Study 1 on more commonly used measures.

\section{Method}

\section{Participants and Design}

Forty-six students (5 men and 41 women) at Utrecht University participated in the study and were paid for their participation. Participants in Experiment 2 were all overpaid and were assigned to one of the two conditions (opponent: friend versus unknown other). 


\section{Experimental Procedure}

Participants were encouraged to bring a friend to the study. Some participants did bring a friend, others did not. Almost all of the participants who did bring a friend were said to be linked to their friend. Participants worked on the experimental tasks and answered the questions that constituted the dependent variables before participating in other, unrelated studies. The studies lasted a total of $30 \mathrm{~min}$, and participants were paid 4 Euros for their participation. Participants were invited to participate in a study on how people perform tasks. On arrival at the laboratory, participants were led to separate cubicles, each of which contained a computer with a monitor and a keyboard. The computers were used to present the stimulus information and to measure the manipulation checks and the dependent variables.

In the first part of the instructions, participants were informed that they would participate in the study with another person. For half of the participants this other person was a friend with whom they had arrived at the laboratory; for the other half this was an unknown other whom they had not met before. The experimental procedure was then outlined to the participants: After the experimental tasks were explained, participants would work on the tasks for $10 \mathrm{~min}$. Furthermore, participants were informed that, after all participants had participated, a lottery would be held among all participants. The winner of this lottery would receive 50 Euros. (Actually, after all participants had completed the study, the 50 Euros were randomly given to a participant; a procedure to which none of the participants objected.) Participants were told that a total of 200 lottery tickets would be divided among all participants. Furthermore, participants were told that after they completed the tasks the experimenter would divide some lottery tickets between them and the other participant. Six practice questions were posed to ensure comprehension of the lottery. If participants gave a wrong answer to a question, the correct answer was disclosed, and the main characteristics of the lottery were repeated.

The tasks were then explained to the participants, and they were asked to answer questions that measured general knowledge for $10 \mathrm{~min}$. They were told that both they and the other participant (friend or unknown other) had to answer the same questions. After these tasks had ended, participants were told how many questions they had answered correctly, and it was communicated to the participants that the other participant had answered an equivalent number of questions correctly (cf. Van den Bos et al., 1997). To assess whether participants thought of the other participant as a person who was comparable in the amount of inputs he or she provided (cf. Van den Bos et al., 1997), they were asked to what extent the other participant had performed well when answering the general knowledge questions relative to the performance of the participant themselves $(1=$ much worse, $4=$ equally, $7=$ much better), to what extent the other participant did his/her best when answering the knowledge questions relative to the participant themselves ( $1=$ much worse, $4=$ equally, $7=$ much better $)$, and to what extent the other participant was good at performing the knowledge questions relative to the participant themselves $(1=$ much worse, $4=$ equally, $7=$ much better $)$.

Participants were then told that the experimenter would divide the lottery tickets between them and the other participant. It was communicated to the participants that 
they received three lottery tickets and that the other participant received one lottery ticket. Participants were then asked questions pertaining to the dependent variables and manipulation checks. Satisfaction judgments were measured by asking participants whether they were satisfied with their outcome $(1=$ very dissatisfied, $7=$ very satisfied $)$ and whether they were content with their outcome $(1=$ very discontent, $7=$ very content $)$. Because participants' answers to these two items were highly correlated $(r=.83, p<.001)$, we averaged their answers to form a reliable scale of satisfaction judgments (alpha $=.89$ ). The response latencies of these satisfaction judgments were the main dependent variables. When participants had answered these questions, and had completed the other studies in which they would participate, they were thoroughly debriefed and paid for their participation.

Results

\section{Additional Measures}

Participants' ratings of the other participant as a comparable person were subjected to a univariate analysis of variance (ANOVA). This ANOVA did not yield significant results. Inspection of the means indicated that participants thought that the other participant worked equally hard, had equally done his or her best, and was equally good in performing the task (overall $M=4.1$ ). Thus, participants thought of the other person as a comparable person.

\section{Satisfaction Judgments}

Participants' outcome satisfaction judgments yielded a significant effect of opponent, $F(1,44)=10.09, p<.01$. As expected, the results showed that participants were less satisfied with being overpaid when their opponent was a friend $(M=4.5, S D=0.3)$ than when their opponent was an unknown other $(M=5.3, S D=0.3)$.

\section{Response Latencies}

Our main dependent variable was the time participants needed to indicate their outcome satisfaction judgments. In Study 2, no participant deviated more than three standard deviations from the mean, so no participants had to be excluded from the data set (Fazio, 1990). As hypothesized, an ANOVA showed a main effect of opponent, $F(1,44)=4.63, p<.05$. Participants needed more time to judge their overpayment when their opponent was a friend $(M=6.7, S D=0.6)$ than when their opponent was an unknown other $(M=4.8, S D=0.6)$.

\section{Discussion}

The findings of Study 2 provide support for our hypothesis that people who are overpaid in reference to a friend, compared to participants who are overpaid in 
reference to an unknown other, need longer to decide whether they are satisfied with this outcome. We assumed that by introducing a friend (compared to an unknown other), participants would experience an increased conflict between hedonic principles and concerns for the other's needs, and should therefore find it more difficult to make satisfaction judgments (Clark \& Mills, 1979; Van Yperen \& Buunk, 1990). In correspondence with this line of reasoning, we indeed found that when a friend was involved in an overpayment situation this resulted in slower satisfaction judgments.

\section{General Discussion}

In two studies we examined how people react to being overpaid relative to another person who is comparable in terms of the amount of inputs provided. In the current article we have argued that overpaid people are in conflict between what they want and what they believe to be right. Furthermore, we have proposed that it will take people more time to respond to being overpaid, compared to reactions to outcome distributions in which no conflict is experienced. The reason being that it is relatively difficult for people to combine the opposing pieces of information they are reacting to when being overpaid. In two studies we have investigated whether support for our hypothesis could be found.

The results of Study 1 give support for the idea that people indeed need longer to decide on their satisfaction when they are overpaid, suggesting that they have to combine sources of information that are opposite to each other: on the one hand, overpaid people receive a relatively high outcome, which makes them pleased, but on the other hand, overpaid people may realize that the outcome is unfair (Messick $\&$ Sentis, 1983). Thus, in line with our predictions, the results of Study 1 suggest that people who are being overpaid indeed might be influenced by two conflicting sources. Furthermore, Study 2 gives additional support for this idea. This study shows that when a friend is present people need longer to respond, suggesting that when being overpaid in reference to a friend the conflict between what makes them pleased and what they believe to be right becomes more difficult.

By providing evidence for our hypothesis using process measures derived from modern social cognition research we have contributed insight into the socialcognitive dynamics of justice reactions. Although the first justice work in social psychology (Adams, 1965) merged concepts that we would now consider social cognition with concerns that arise in interpersonal relationships, much of the next three decades of social justice research was absorbed in documenting the importance of justice judgments and in analyzing the social psychology of justice largely from motivational perspectives (De Cremer \& Tyler, 2005; Tyler \& Lind, 1992). During those years, relatively less attention was given to the social-cognitive dynamics involved in generating social justice judgments (there were, however, some notable exceptions; see, e.g., Hafer, 2000; Steiner, Guirard, \& Baccino, 1999). Recently, a new wave of social justice research has begun investigating how people react toward justice issues (e.g., Brockner \& Wiesenfeld, 1996; Van den Bos, 2001; Van Prooijen, Karremans, \& Van Beest, 2006), and the findings of this research 
have helped social psychology to generate new models of social justice (e.g., Brockner \& Wiesenfeld, 1996; Van den Bos \& Lind, 2002) or to refine insights into existing justice theories and other important social psychological frameworks (e.g., Van den Bos, Poortvliet, Maas, Miedema, \& Van den Ham, 2005; Van den Bos \& Van Prooijen, 2001). The studies reported in the current article continue this new line of social justice research by testing people's precise reactions toward being better paid than comparable other persons, hence introducing process-oriented research in equity theory and equity research.

Besides conducting process-oriented research, another fruitful avenue for future research may be to examine the precise emotions that are the result of people being overpaid. Most equity researchers argue that people are only moderately satisfied with being overpaid because they feel guilty (e.g., Hassebrauck, 1986; Homans, 1974; Van Yperen \& Buunk, 1990; Walster et al., 1978). Peters (2005), however, proposed that the concept of guilt is not always needed to explain people's reactions to being overpaid. In real life, people often have little influence on being better off than others as they, for instance, cannot help being born in a country or family that has better access to certain resources. Related to this, in a typical equity experiment, participants also do not often have influence on their outcomes as participants simply receive an outcome from an experimenter. Because people do not generally feel guilty about things they have not caused themselves (Arendt, 1968, 2005; Frijda, 1986; Roseman, Wiest, \& Swartz, 1994; Tangney, 1991; Tangney, Miller, Flicker, \& Barlow, 1996), Peters (2005) proposed that instead of feelings of guilt, feelings of uneasiness might better explain people's moderate levels of satisfaction with overpayment. Her research findings provide evidence that supports this proposition (see also Adams \& Freedman, 1976), but future research is needed to sort out under what conditions guilt or uneasiness explain how people react to being overpaid.

To return to the findings presented in the current article, we would like to emphasize that by means of the studies presented here, we got a closer look at how people react to being advantaged. The results of these studies suggest that it is relatively difficult for people to make satisfaction judgments regarding outcomes in which they are advantaged, especially when a friend is the one who is disadvantaged. By means of these studies presented here, as well as in other recent research studies (e.g., Peters, 2005; Peters et al., 2004; Van den Bos et al., 2006), justice researchers get a closer look at the intriguing issue of how advantaged people react to being overpaid. In doing so, the present studies have made a contribution to the existing literature about people's reactions to being overpaid and this may contribute to more precise insights into the psychology of equity processes. Thus, with the current research we hope to have enlarged the understanding of how people react to being overpaid in particular, and to have contributed more generally to insights into the psychology of the advantaged in this world.

Acknowledgements The work in this article was supported by grants from the Netherlands Organization for Scientific Research (410-21-005-P and VICI 453.03.603). We would like to thank Dirk Steiner for his valuable comments on a previous version of this article. 
Open Access This article is distributed under the terms of the Creative Commons Attribution Noncommercial License which permits any noncommercial use, distribution, and reproduction in any medium, provided the original author(s) and source are credited.

\section{References}

Adams, J. S. (1965). Inequity in social exchange. In L. Berkowitz (Ed.), Advances in experimental social psychology. (Vol. 2, pp. 267-299). New York: Academic Press.

Adams, J. S., \& Freedman, S. (1976). Equity theory revisited: Comments and annotated bibliography. In L. Berkowitz \& E. Walster (Eds.), Equity theory: Toward a general theory of social interaction. New York: Academic Press.

Arendt, H. (1968). Men in dark times. New York: Harcourt, Brace, \& World.

Arendt, H. (2005). Responsibility and judgment. New York: Schocken.

Aron, A., Aron, E. N., Tudor, M., \& Nelson, G. (1991). Close relationships as including other in self. Journal of Personality and Social Psychology, 60, 241-253.

Austin, W. (1977). Equity theory and social comparison processes. In J. Suls \& R. Miller (Eds.), Social comparison theory: Theoretical and empirical perspectives (pp. 279-305). Washington, DC: Hemisphere.

Austin, W., McGinn, N. C., \& Susmilch, C. (1980). Internal standards revisited: Effects of social comparisons and expectancies on judgments of fairness and satisfaction. Journal of Experimental Social Psychology, 16, 426-441.

Austin, W., \& Walster, E. (1974). Reactions to confirmations and disconfirmations of expectancies of equity and inequity. Journal of Personality and Social Psychology, 30, 208-216.

Berkowitz L., Walster E. (Eds). (1976). Advances in experimental social psychology: Equity theory, toward a general theory of social interaction (Vol. 9). New York: Academic Press.

Brockner, J., \& Wiesenfeld, B. M. (1996). An integrative framework for explaining reactions to decisions: Interactive effects of outcomes and procedures. Psychological Bulletin, 120, 189-208.

Buunk, B. P., \& Van Yperen, N. W. (1989). Social comparison, equality, and relationship satisfaction: Gender differences over a ten-year period. Social Justice Research, 3, 157-180.

Buunk, B. P., \& Van Yperen, N. W. (1991). Referential comparisons, relational comparisons, and exchange orientation: Their relation to marital satisfaction. Personality and Social Psychology Bullitien, 17, 709-717.

Clark, M. S., \& Mills, J. (1979). Interpersonal attraction in exchange and communal relationships. Journal of Personality and Social Psychology, 37, 12-24.

De Cremer, D., \& Tyler, T. R. (2005). Managing group behavior: The interplay between procedural justice, sense of self, and cooperation. In M. P. Zanna (Ed.), Advances in experimental social psychology. (Vol. 37, pp. 151-218). San Diego, CA: Academic Press.

Fazio, R. H. (1990). A practical guide to the use of response latency in social psychological research. In C. Hendrick \& M. S. Clark (Eds.), Research methods in personality and social psychology (pp. 7497). Newbury Park, CA: Sage.

Fiske, S. T., \& Taylor, S. E. (1991). Social cognition. New York: McGraw-Hill.

Frijda, N. H. (1986). The emotions. Cambridge: Cambridge University Press.

Greenberg, J. (1982). Approaching equity and avoiding inequity in groups and organizations. In J. Greenberg \& R. L. Cohen (Eds.), Equity and justice in social behavior (pp. 389-435). New York: Academic Press.

Hafer, C. L. (2000). Do innocent victims threaten the belief in a just world? Evidence from a modified Stroop task. Journal of Personality and Social Psychology, 79, 165-173.

Hassebrauck, M. (1986). Ratings of distress as a function of degree and kind of inequity. Journal of Social Psychology, 126, 269-270.

Homans, G. C. (1974). Social behavior: Its elementary forms. New York: Harcourt, Brace.

Jacques, E. (1961). Equitable payment. London: Heinemann.

Kunda, Z. (1999). Social cognition: Making sense of people. Cambridge, MA: The MIT Press.

Loewenstein, G. F., Thompson, L., \& Bazerman, M. H. (1989). Social utility and decision making in interpersonal contexts. Journal of Personality and Social Psychology, 57, 426-441. 
Messick, D. M., \& Sentis, K. P. (1983). Fairness, preference, and fairness biases. In D. M. Messick \& K. S. Cook (Eds.), Equity theory: Psychological and sociological perspectives (pp. 61-94). New York: Praeger.

Mikula, G. (2003). Testing an attribution-of-blame model of judgments of injustice. European Journal of Social Psychology, 33, 793-811.

Montada, L. (2002). Doing justice to the justice motive. In M. Ross \& D. T. Miller (Eds.), The justice motive in everyday life. New York: Cambridge University Press.

Montada, L., Schmitt, M., \& Dalbert, C. (1986). Thinking about justice and dealing with one's own privileges. In H. W. Bierhoff, R. L. Cohen, \& J. Greenberg (Eds.), Justice in social relations. New York: Plenum.

Peters, S. L. (2005). The social psychology of being better off than others. Unpublished doctoral dissertation, Utrecht University, Utrecht, The Netherlands.

Peters, S. L., Van den Bos, K., \& Bobocel, D. R. (2004). The moral superiority effect: Self versus other differences in satisfaction with being overpaid. Social Justice Research, 17, 257-273.

Rawls, J. (1971/1999). A theory of justice. Cambridge: Harvard University Press.

Roseman, I. J., Wiest, C., \& Swartz, T. S. (1994). Phenomenology, behaviors, and goals differentiate discrete emotions. Journal of Personality and Social Psychology, 67, 206-221.

Steiner, D. D., Guirard, S., \& Baccino, T. (1999, May). Cognitive processing of procedural justice information: Application of the Oculometer. Paper presented at the Annual Conference of the Society for Industrial/Organizational Psychology, Atlanta, GA.

Tangney, J. P. (1991). Moral affect: The good, the bad, and the ugly. Journal of Personality and Social Psychology, 61, 598-607.

Tangney, J. P., Miller, R. S., Flicker, L., \& Barlow, D. H. (1996). Are shame, guilt, and embarrassment distinct emotions? Journal of Personality and Social Psychology, 70, 1256-1269.

Tyler, T. R., Boeckmann, R. J., Smith, H. J., \& Huo, Y. J. (1997). Social justice in a diverse society. Boulder, CO: Westview Press.

Tyler, T. R., \& Lind, E. A. (1992). A relational model of authority in groups. In M. P. Zanna (Ed.), Advances in experimental social psychology (Vol. 25., pp. 115-191). San Diego, CA: Academic Press.

Van den Bos, K. (2001). Uncertainty management: The influence of uncertainty salience on reactions to perceived procedural fairness. Journal of Personality and Social Psychology, 80, 931-941.

Van den Bos, K., \& Lind, E. A. (2002). Uncertainty management by means of fairness judgments. In M. P. Zanna (Ed.) Advances in experimental social psychology (Vol. 34, pp. 1-60). San Diego, CA: Academic Press.

Van den Bos, K., Lind, E. A., Vermunt, R., \& Wilke, H. A. M. (1997). How do I judge my outcome when I do not know the outcome of others? The psychology of the fair process effect. Journal of Personality and Social Psychology, 72, 1034-1046.

Van den Bos, K., Peters, S. L., Bobocel, D. R., \& Ybema, J. F. (2006). On preferences and doing the right thing: Satisfaction with advantageous inequity when cognitive processing is limited. Journal of Experimental Social Psychology, 42, 273-289.

Van den Bos, K., Poortvliet, P. M., Maas, M., Miedema, J., \& Van den Ham, E.-J. (2005). An enquiry concerning the principles of cultural norms and values: The impact of uncertainty and mortality salience on reactions to violations and bolstering of cultural worldviews. Journal of Experimental Social Psychology, 41, 91-113.

Van den Bos, K., \& Van Prooijen, J.-W. (2001). Referent cognitions theory: The role of closeness of reference points in the psychology of voice. Journal of Personality and Social Psychology, 81, 616626.

Van den Bos, K., Wilke, H. A. M., Lind, E. A., \& Vermunt, R. (1998). Evaluating outcomes by means of the fair process effect: Evidence for different processes in fairness and satisfaction judgments. Journal of Personality and Social Psychology, 74, 1493-1503.

Van Prooijen, J.-W., Karremans, J. C., \& Van Beest, I. (2006). Procedural justice and the hedonic principle: How approach versus avoidance motivation influences the psychology of voice. Journal of Personality and Social Psychology, 91, 686-697.

Van Yperen, N. W., \& Buunk, B. P. (1990). A longitudinal study of equity and satisfaction in intimate relationships. European Journal of Social Psychology, 20, 287-309.

Walster, E., Berscheid, E., \& Walster, G. W. (1973). New directions in equity research. Journal of Personality and Social Psychology, 25, 151-176.

Walster, E., Walster, G. W., \& Berscheid, E. (1978). Equity: Theory and research. Boston: Allyn \& Bacon. 